Supporting Information for

\title{
Charge Neutralization Strategy to Construct Salt-Tolerant and Cell-Permeable Nanoprobes: Application in Ratiometric Sensing and Imaging of Intracellular pH
}

Jiating Cao, ${ }^{\dagger}$ Meiting Xie,$^{\dagger}$ Xinyu Gao, ${ }^{\dagger}$ Zhuoyong Zhang, ${ }^{\dagger}$ Jianguo Wang, ${ }^{\dagger}$ Wenjuan Zhou, ${ }^{*}{ }^{\dagger}$ Weijiang Guan, ${ }^{\S}$ and Chao $\mathrm{Lu}^{\S}$

${ }^{\dagger}$ Department of Chemistry, Capital Normal University, Beijing 100048, China

${ }^{\ddagger}$ Inner Mongolia Key Laboratory of Fine Organic Synthesis, College of Chemistry and Chemical Engineering, Inner Mongolia University, Hohhot 010021, China

${ }^{\S}$ State Key Laboratory of Chemical Resource Engineering, Beijing University of Chemical Technology, Beijing 100029, China

Email: zhouwenjuan@cnu.edu.cn; Email: wjguan@mail.buct.edu.cn 


\section{Contents}

Figure S1. TEM image of the GSH-AuNCs. - - -

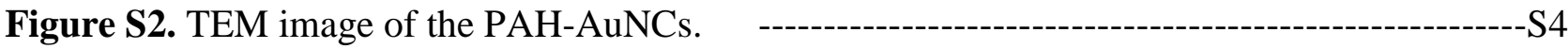

Figure S3. Fluorescence spectra of HPTS and PAH-HPTS. - -

Figure S4. Fluorescence spectra of HPTS excited by (A) $405 \mathrm{~nm}$ and (B) $450 \mathrm{~nm}$, respectively. -S6

Figure S5. (A) Spectral overlap between the absorption spectrum of GSH-AuNCs and the fluorescence spectrum of HPTS. (B) Absorption spectra of the GSH-AuNCs in different pHs. - $\quad$-S7 Figure S6. Fluorescence spectra of PAH-HPTS at different pH values. - --------------------------S8

Figure S7. Fluorescence spectra of GSH-AuNCs at different pH values. - ----------------------S9

Figure S8. Fluorescence spectra of PAH-AuNCs at different $\mathrm{pH}$ values.

Figure S9. The fluorescence intensity ratios $\left(I_{641} / I_{518}\right)$ of HPTS-PAH-AuNCs in the presence of different interferences $(100 \mu \mathrm{M}, \mathrm{pH}=7.0)$.

Figure S10. Ratiometric fluorescence response $\left(I_{641} / I_{518}\right)$ of HPTS-PAH-AuNCs to $\mathrm{pH}$ in the presence of $10 \mathrm{mM}$ of GSH.

Figure S11. Cells viability of HeLa cells incubated with different concentrations of the HPTA-PAH-AuNCs for $24 \mathrm{~h}$.

Figure S12. Fluorescence images from green channel of HeLa cells incubated with HPTS and HPTS-PAH-AuNCs for $4 \mathrm{~h}$.

Figure S13. Correlation of HPTS-PAH-AuNCs (green channel) and Lyso-Tracker Red (red channel).

Table S1. Comparison between the performance of HPTS-PAH-AuNCs and other AuNC-based ratiometric fluorescence probes reported in the literatures. 


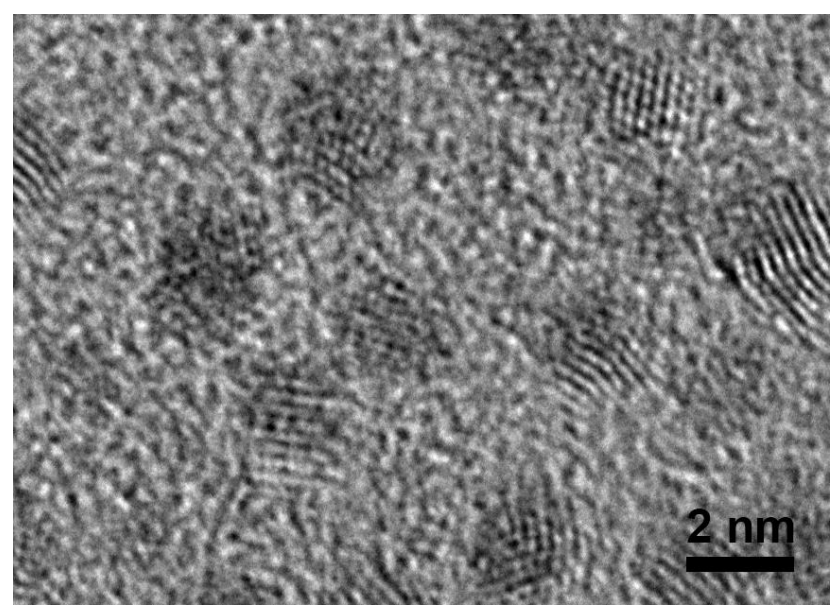

Figure S1. TEM image of the GSH-AuNCs. 


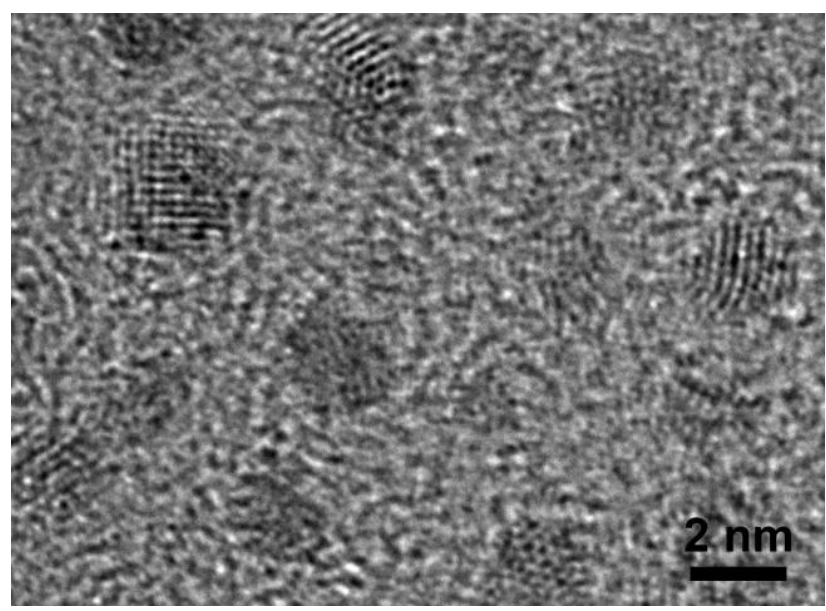

Figure S2. TEM image of the PAH-AuNCs. 


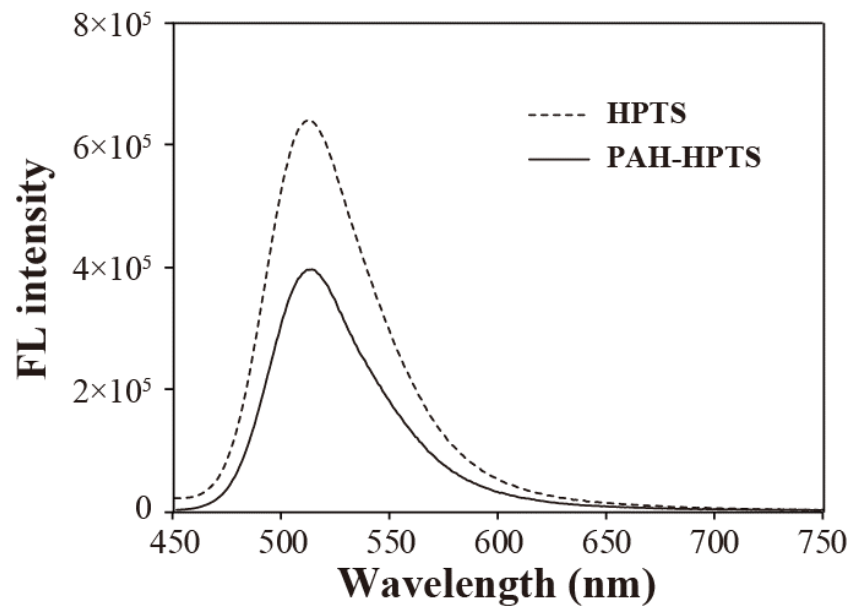

Figure S3. Fluorescence spectra of HPTS and PAH-HPTS. 

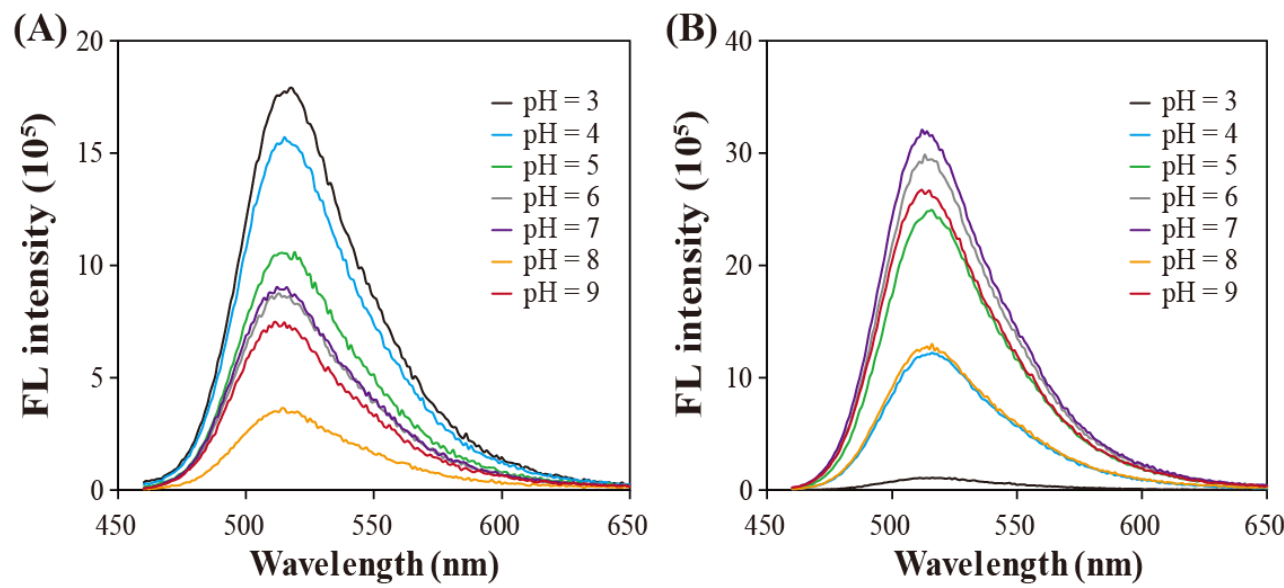

Figure S4. Fluorescence spectra of HPTS excited by (A) $405 \mathrm{~nm}$ and (B) $450 \mathrm{~nm}$, respectively. 

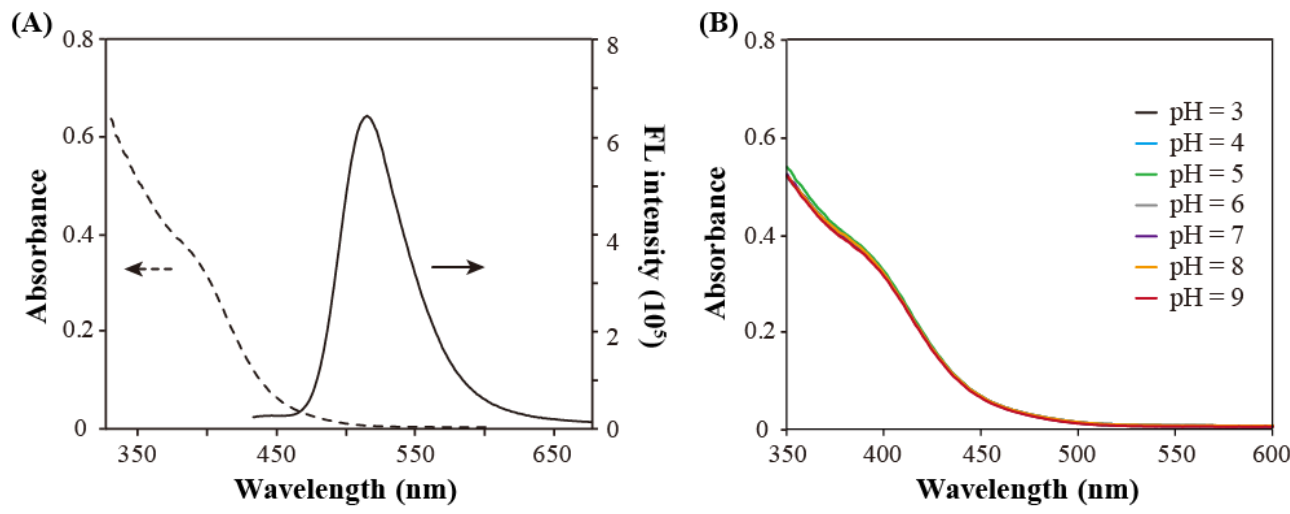

Figure S5. (A) Spectral overlap between the absorption spectrum of GSH-AuNCs and the fluorescence spectrum of HPTS. (B) Absorption spectra of the GSH-AuNCs in different pHs. 


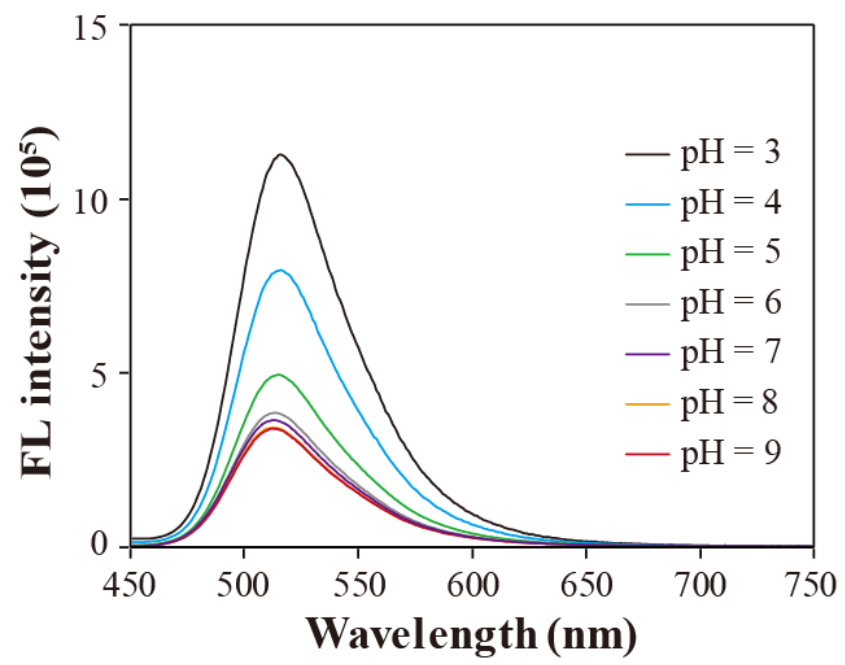

Figure S6. Fluorescence spectra of PAH-HPTS at different $\mathrm{pH}$ values. 


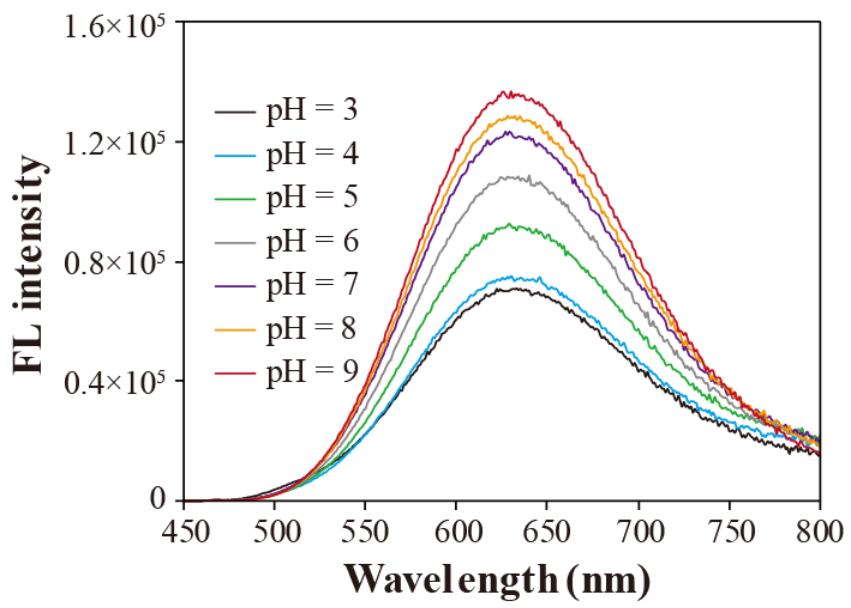

Figure S7. Fluorescence spectra of GSH-AuNCs at different $\mathrm{pH}$ values. 


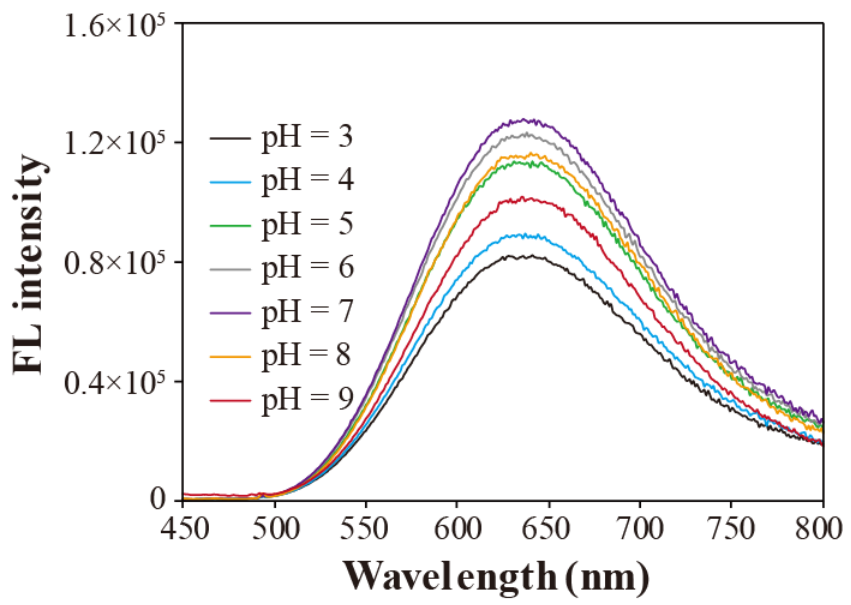

Figure S8. Fluorescence spectra of PAH-AuNCs at different $\mathrm{pH}$ values. 


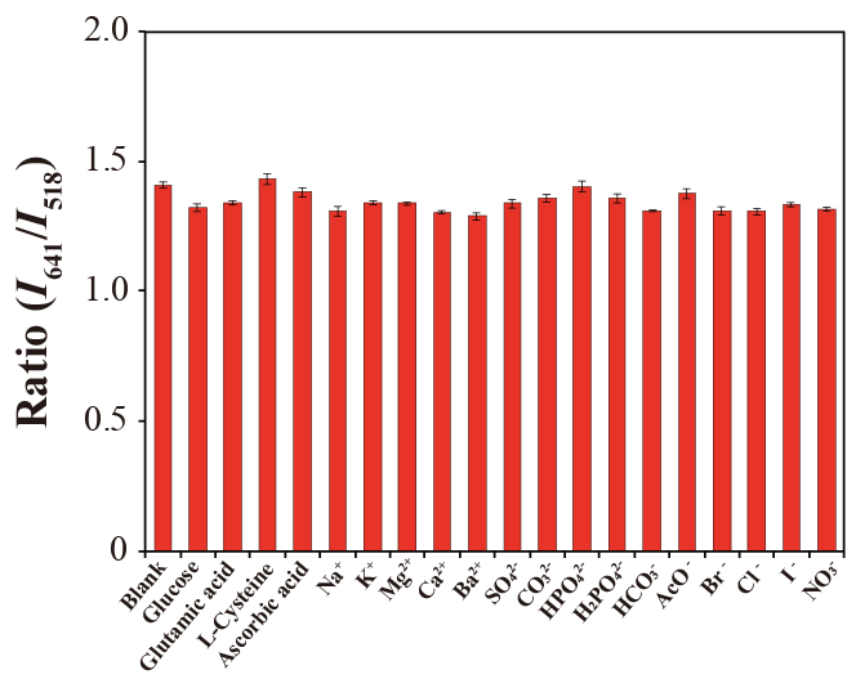

Figure S9. The fluorescence intensity ratios $\left(I_{641} / I_{518}\right)$ of HPTS-PAH-AuNCs in the presence of different interferences $(100 \mu \mathrm{M}, \mathrm{pH}=7.0)$. 


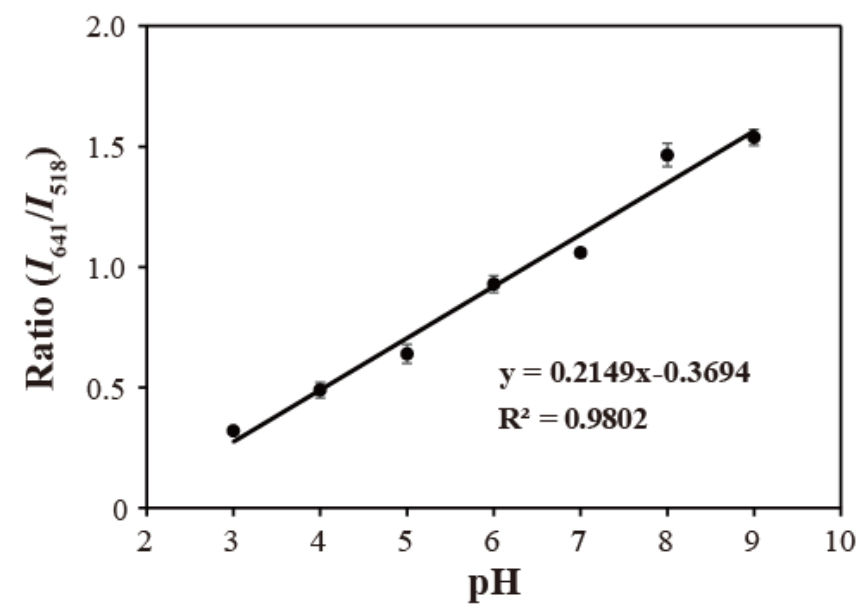

Figure S10. Ratiometric fluorescence responses $\left(I_{641} / I_{518}\right)$ of HPTS-PAH-AuNCs to $\mathrm{pH}$ in the presence of $10 \mathrm{mM}$ of GSH. 


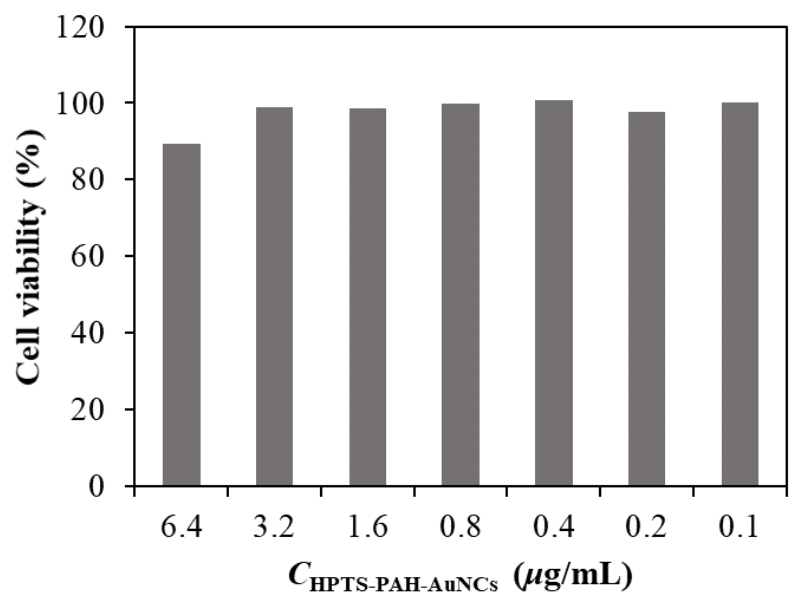

Figure S11. Cells viability of HeLa cells incubated with different concentrations of the HPTS-PAH-AuNCs for $24 \mathrm{~h}$. 

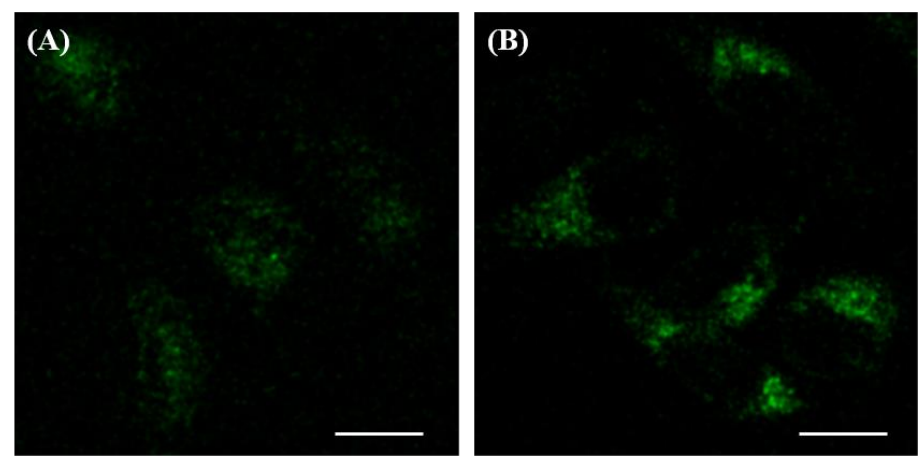

Figure S12. Fluorescence images from green channel $\left(480-550 \mathrm{~nm}, \lambda_{\mathrm{ex}}=405 \mathrm{~nm}\right)$ of HeLa cells incubated with (A) HPTS (average gray value: 15) and (B) HPTS-PAH-AuNCs (average gray value: 28) for $4 \mathrm{~h}$. Scale bars, $10 \mu \mathrm{m}$. 


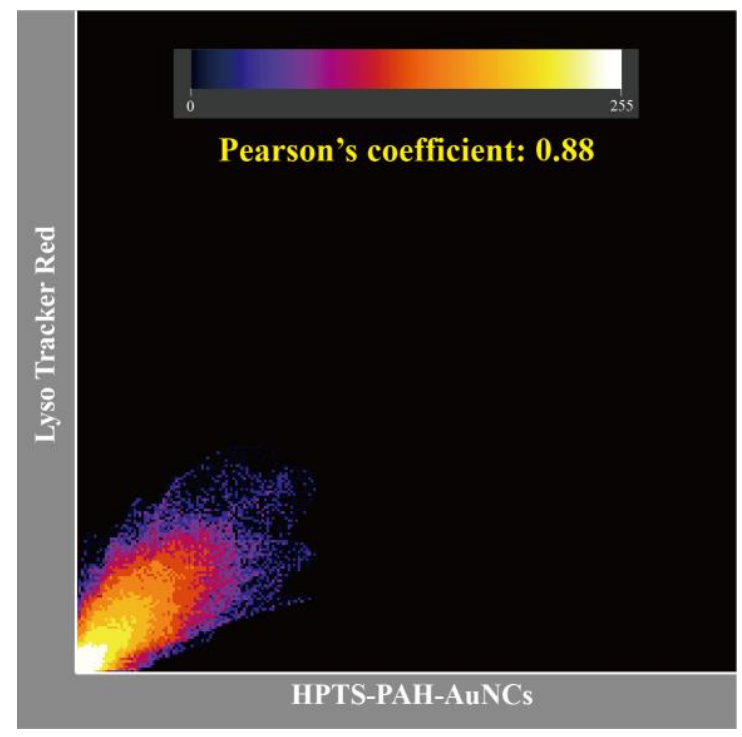

Figure S13. Correlation of HPTS-PAH-AuNCs (green channel) and Lyso-Tracker Red (red channel). 
Table S1. Comparison between the performance of HPTS-PAH-AuNCs and other AuNC-based ratiometric fluorescence probes reported in the literatures.

\begin{tabular}{|c|c|c|c|c|c|}
\hline Probe & pH range & Response time & pH resolution & $\lambda_{\mathrm{em}}$ & $\operatorname{Ref}^{a}$ \\
\hline FITC-BSA-AuNCs & $6.0-7.8$ & $30 \mathrm{~s}$ & $0.1 \mathrm{pH}$ & $516 \mathrm{~nm} / 625 \mathrm{~nm}$ & 1 \\
\hline FITC-FPen-AuNCs & $5.0-9.5$ & - & $0.1 \mathrm{pH}$ & $521 \mathrm{~nm} / 635 \mathrm{~nm}$ & 2 \\
\hline BSA-Ce/Au NCs & $6.0-9.0$ & - & $0.5 \mathrm{pH}$ & $410 \mathrm{~nm} / 650 \mathrm{~nm}$ & 3 \\
\hline LysNP-AuNCs & $7.5-9.5$ & - & $0.2 \mathrm{pH}$ & $495 \mathrm{~nm} / 767 \mathrm{~nm}$ & 4 \\
\hline NAD-AuNCs & $3.0-11.0$ & - & - & $417 \mathrm{~nm} / 468 \mathrm{~nm}$ & 5 \\
\hline NADP-AuNCs & $\begin{array}{l}0.6-2.7 \\
7.0-9.2\end{array}$ & 一 & $0.2 \mathrm{pH}$ & $417 \mathrm{~nm} / 470 \mathrm{~nm}$ & 6 \\
\hline HPTS-PAH-AuNCs & $3.0-9.0$ & $<30 \mathrm{~s}$ & $0.5 \mathrm{pH}$ & $518 \mathrm{~nm} / 641 \mathrm{~nm}$ & Our work \\
\hline
\end{tabular}

${ }^{\mathrm{a} A u N C-b a s e d ~ r a t i o m e t r i c ~ f l u o r e s c e n c e ~ p r o b e s ~ r e p o r t e d . ~}$

\section{References}

(1) Ding, C. Q.; Tian, Y. Biosens. Bioelectron. 2015, 65, 183-190.

(2) Yang, Y.; Xia, M. C.; Zhao, H. S.; Zhang, S. C.; Zhang, X. R. ACS Sensors 2018, 3, 2278-2285.

(3) Chen, Y. N.; Chen, P. C.; Wang, C. W.; Lin, Y. S.; Ou, C. M.; Ho, L. C.; Chang, H. T. Chem. Commun. 2014, 50, $8571-8574$.

(4) Chandirasekar, S.; You, J. G.; Xue, J. H.; Tseng, W. L. J. Mater. Chem. B 2019, 7, 3876-3883.

(5) Cuaran-Acosta, D.; Londoño-Larrea, P.; Zaballos-García, E.; Pérez-Prieto, J. Chem. Commun. 2019, 55, $1604-1606$.

(6) Bonanno, A.; Pérez-Herráez, I.; Zaballos-García, E.; Pérez-Prieto, J. Chem. Commun. 2020, 56, 587-590. 